\title{
Gastric band migration to gastrointestinal lumen and possibilities of its surgical treatment
}

\author{
Anna Sawicka-Pierko ${ }^{1, A-D}$, Jacek Pierko 2,A-D, Monika Krawczyk²,B, Jerzy R. Ładny'2,E,F, Jacek Dadan²,E,F, Hady Razak Hady 2,A,E,F \\ ${ }^{1}$ Department of Ophthalmology, Medical University of Bialystok, Poland

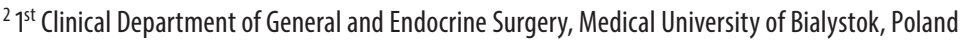 \\ A - research concept and design; $\mathrm{B}$ - collection and/or assembly of data; $\mathrm{C}$ - data analysis and interpretation; \\ $D$ - writing the article; $E$ - critical revision of the article; $F$ - final approval of the article
}

\section{Address for correspondence \\ Jacek Pierko}

E-mail: jacekpierko@gmail.com

Funding sources

None declared

Conflict of interest

None declared

Received on October 21, 2016

Reviewed on December 6, 2016

Accepted on February 5, 2018

Published online on November 23, 2018
Cite as

Sawicka-Pierko A, Pierko J, Krawczyk M, Ładny J, Dadan J, Hady R. Gastric band migration to gastrointestinal lumen and possibilities of its surgical treatment. Adv Clin Exp Med. 2019;28(1):103-107. doi:10.17219/acem/85060

DOI

$10.17219 /$ acem $/ 85060$

\section{Copyright}

Copyright by Author(s)

This is an article distributed under the terms of the

Creative Commons Attribution Non-Commercial License

(http://creativecommons.org/licenses/by-nc-nd/4.0/)

\begin{abstract}
Background. Due to numerous late complications after laparoscopic adjustable gastric banding (LAGB), leading to band removal, a significant decrease of its application has been observed.

Objectives. The objective of this study was to present complications after LAGB in our own material.

Material and methods. The study included 152 obese patients who underwent LAGB between 2005 and 2012. The group of women consisted of 91 patients (60\%) with the following preoperative parameters: average body mass index (BMI) $42 \pm 3.66 \mathrm{~kg} / \mathrm{m}^{2}$ and average body mass $122 \pm 12.8 \mathrm{~kg}$. The group of men included 61 patients (40\%) with a preoperative average BMl $43 \pm 3.81 \mathrm{~kg} / \mathrm{m}^{2}$ and average body mass $125 \pm 13.02 \mathrm{~kg}$. The average age of women was $35.02 \pm 11.6$ years and of men $36.18 \pm 10.5$ years.
\end{abstract}

Results. Among 152 patients after LAGB due to morbid obesity, in 7 (4.6\%) migration of the band to the stomach lumen was observed, in 4 port wound purulence occurred, in 3 stomach mucosa ulceration was diagnosed in the band pressure area, 3 reported heartburn and hyperacidity, and 4 suffered from emesis. In all aforementioned patients, body mass loss stopped and they reported lack of restriction after last band regulation.

Conclusions. Surgical or endoscopic treatment in patients with a migrated band is an individual matter depending on the type and size of band dislocation, its clinical symptoms and the general state of the patient, but also on the experience of the operating team and the quality of the equipment.

Key words: band migration, obesity, laparoscopic adjustable gastric banding, bariatric surgery 


\section{Introduction}

The number of cases of morbid obesity is constantly growing - it is estimated that in 2016 the number of adults with overweight will oscillate around 2.3 billion and of obese adults will exceed 70 million. ${ }^{1,2}$ In almost every country, obesity is an epidemic, which explains the recent intensive development of bariatric surgery. Surgical treatment is now a method of choice in obese patients who did not reveal satisfying effects after preservative treatment. ${ }^{3}$

In our department, the following procedures are performed as a routine: sleeve gastrectomy (SG), gastric bypass (GBP) and laparoscopic adjustable gastric banding (LAGB); however, in the last 3 years, there has been an $80 \%$ decrease in gastric banding procedures. It is worth mentioning that we performed an endoscopic evacuation of a migrated band for the first time in Poland. As with every surgical intervention, bariatric surgery brings the risk of perioperative complications; however, obese patients are a very specific group, according to the rule: big patient - big risk. ${ }^{4}$

Surgical treatment of obesity using the adjustable gastric band (AGB) became possible after research commenced in the 1980s. Laparoscopic adjustable gastric banding, started and developed by Guy-Bernard Cadière and Franco Favretti, is the least invasive method among bariatric procedures.

In Poland, this procedure was applied for the first time in 1998. Currently, it is estimated that adjustable gastric banding is the most frequently applied procedure in the USA and Australia, while in Europe, a significant decrease in its application has been noted due to numerous late complications, leading to band removal.

The undisputed advantages of this procedure are the following: lack of anatomy alteration, the possibility of band removal if needed, no necessity of nutritional supplementation in the postoperative period, and low frequency of complications occurrence, comparable to other bariatric procedures despite their different characteristic. ${ }^{3,5}$

A possible early complication after LAGB is bleeding from the port-site incision. The following perioperative complications are also worth noting: damage and bleeding from the diaphragm and organs such as stomach, liver and spleen. Late postoperative complications include band slippage, its migration to the gastrointestinal lumen, pouch dilatation, mucositis and esophagus dilatation, stomach mucosa ulceration in the place of band pressure, heartburn, hyperacidity, emesis, lost connection between band and its port, as well as body mass loss discontinuance. ${ }^{6,7}$

\section{Material and methods}

The study included 152 obese patients who underwent LAGB between 2005 and 2012. The group of women consisted of 91 patients $(60 \%)$ with the following preoperative parameters: average body mass index (BMI) $42 \pm 3.66 \mathrm{~kg} / \mathrm{m}^{2}$ and average body mass $122 \pm 12.8 \mathrm{~kg}$. The group of men included 61 patients (40\%) with a preoperative average BMI $43 \pm 3.81 \mathrm{~kg} / \mathrm{m}^{2}$ and average body mass $125 \pm 13.02 \mathrm{~kg}$. The average age of women was $35.02 \pm 11$. 6 years and of men $36.18 \pm 10.5$ years (Table 1 ).

Patients were qualified for LAGB according to Polish recommendations based on European guidelines taking into account principles of evidence-based medicine (EBM) $)^{8,9}$ after an analysis of the results of precise laboratory tests and a series of multispecialistic consultations.

An abdominal medical ultrasonography (USG) and a gastroscopy allowed us to exclude any pathologies which would disqualify the patient from the surgery. Furthermore, the following examinations had been conducted in order to exclude other contraindications for surgical treatment: endocrinological examination, cardiological examination in patients with cardiovascular dysfunction, gynecological examination in women, dietetic examination, and psychological examination. The aforementioned consultations minimized the perioperative risk and intensified the postsurgical effect.

Adjustable gastric banding was performed laparoscopically with general anesthesia, using 4-5 trocars. A pars flaccida approach and multiple banding-perigastric technique was applied as a method of entrance. The further stage of the operation involved exposing the posterior wall of the stomach and reaching the His angle using the Goldfinger device or a grasper and, lastly, introducing a silicone ring and closing it under the cardia by creating a small pouch (approx. $25 \mathrm{~mL}$ ).

Finally, the ring was connected with a regulation port, placed in subcutaneous tissue under the left costal arch, using a drain. In the majority of cases, the average time of hospitalization was 3 days. One of the postoperative recommendations was a 2 -week semi-liquid, low-calorie and low-carbohydrate. Further recommendations included a control visit in an outpatient clinic once a month. The first regulation was conducted 6 weeks after the surgery and further regulations were applied every 3-6 months.

\section{Results}

Among 152 patients after LAGB due to morbid obesity, in 7 (4.6\%) migration of the band to the stomach lumen was observed, port wound purulence occurred in 4 patients,

Table 1. Characteristics of patients

\begin{tabular}{|l|c|c|}
\multicolumn{1}{|c|}{ Variables } & Female & Male \\
\hline Number of patients & 91 & 61 \\
\hline Body mass $[\mathrm{kg}]$ & $122 \pm 12.8$ & $125 \pm 13.02$ \\
\hline Age $[\mathrm{years}]$ & $35 \pm 11.6$ & $36.18 \pm 10.05$ \\
\hline BMI $\left[\mathrm{kg} / \mathrm{m}^{3}\right]$ & $42 \pm 3.66$ & $43 \pm 3.81$ \\
\hline
\end{tabular}

Data presented as mean \pm standard deviation (SD);

$\mathrm{BMI}$ - body mass index. 


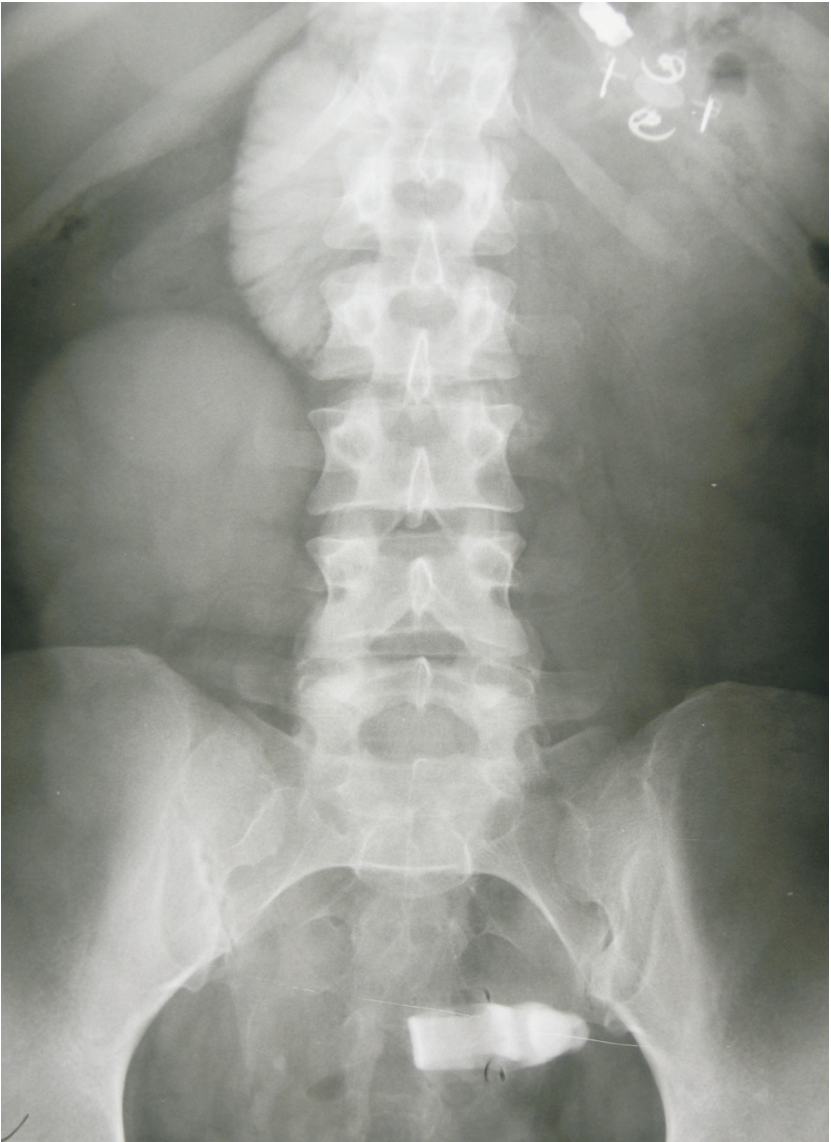

Fig. 1. X-ray. Migration of the band to the stomach lumen followed by its replacement to the small intestine

stomach mucosa ulceration was diagnosed in the band pressure area in 3 patients, 3 patients reported heartburn and hyperacidity, and 4 patients suffered from emesis (Table 2).

In all the aforementioned patients, body mass loss stopped, even weight gain was observed, and they reported lack of restriction after the last band regulation. The following imaging diagnostics were conducted: thorax and abdominal X-ray, esophagus and stomach contrast X-ray, gastroscopy, abdominal USG, and computed tomography $(\mathrm{CT})$. Further treatment depended on the general condition of the patient, clinical symptoms of gastric band migration and the type of band allocation.

We observed 1 case of a 27-year-old patient who suffered from pain, port infection and symptoms of peritonitis 38 months after LAGB. In this period, she underwent 9 band regulations. Abdominal X-ray revealed band migration to the lower pelvis (Fig. 1). The patient underwent reconnoitering laparoscopy showing the presence of a 12-centimeter linear perforation of the anterior wall of the stomach and band migration to the small intestine, $50-60 \mathrm{~cm}$ from Treitz ligament, with partial necrosis of the intestinal wall in this area $(10-15 \mathrm{~cm})$. The operating team decided perioperatively to continue with the classical method. The band was removed

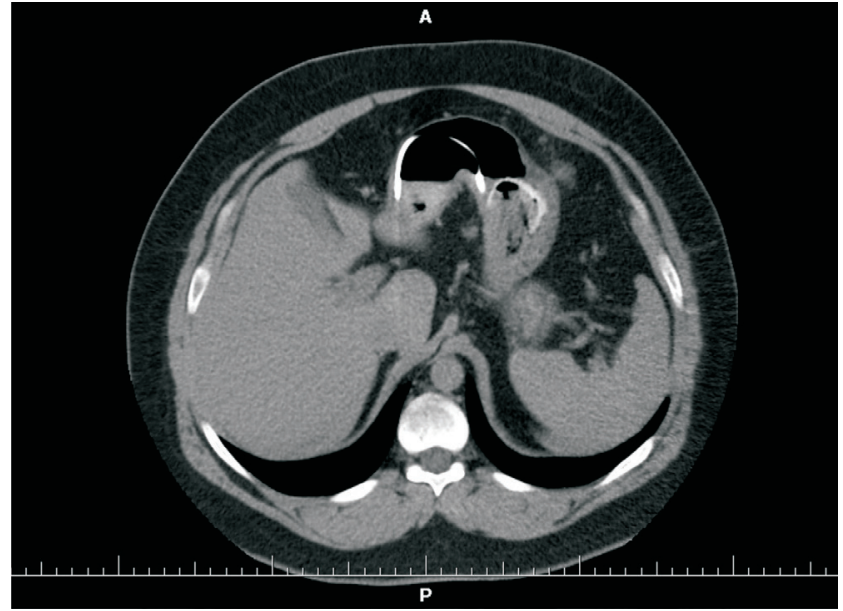

Fig. 2. Computed tomography (CT). Partial migration of the band to the stomach

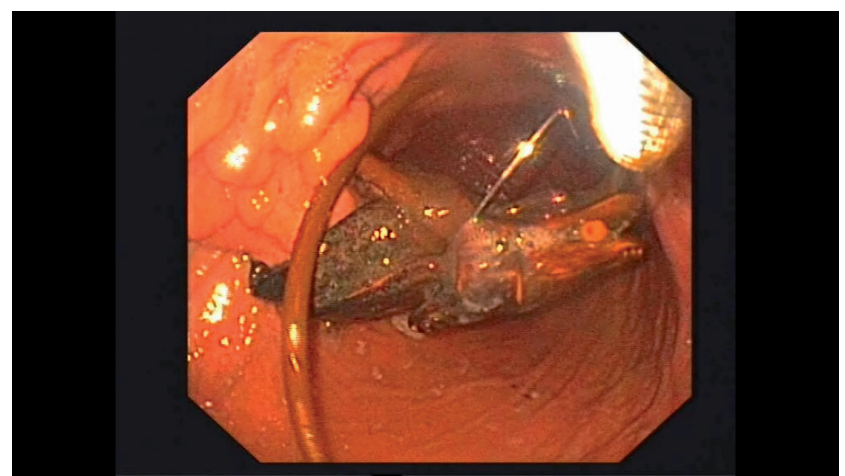

Fig. 3. Gastroscopy. Removal of the relocated band

with a partial small intestine resection and end-to-end anastomosis; perforation of the stomach wall was dressed surgically. What is more, the abscesses created between the intestines were evacuated, and the abdominal cavity was rinsed and drained (3 drains were applied).

In 4 out of 7 patients in this group, a partial dislocation of AGB occurred. In 3 cases 2/3 (Fig. 2) and in 1 case 3/4 of the band migrated to the stomach lumen (Fig. 3).

Treatment included port removal from the abdomen, introduction of a drain connecting the port and the band with the peritoneal cavity, and finally, endoscopic removal of the band from the stomach lumen. Postoperative

Table 2. Migration of the band to the stomach lumen including number of regulations and percentage of excess weight loss (\%EWL)

\begin{tabular}{|c|c|c|c|c|c|c|}
$\begin{array}{c}\text { Patient } \\
\text { number }\end{array}$ & Patient & Age & BMI & $\begin{array}{c}\% \text { EWL } \\
\text { year 1/2/3 }\end{array}$ & $\begin{array}{c}\text { Migration } \\
\text { month }\end{array}$ & $\begin{array}{c}\text { Number } \\
\text { of regulations }\end{array}$ \\
\hline 1 & F & 47 & 45 & $64 / 61 / 45$ & 36 & 8 \\
\hline 2 & F & 27 & 43 & $66 / 58 / 38$ & 38 & 9 \\
\hline 3 & F & 44 & 42 & $61 / 54 / 34$ & 32 & 4 \\
\hline 5 & F & 36 & 41 & $70 / 56 / 28$ & 36 & 10 \\
\hline 6 & M & 35 & 44 & $51 / 63 / 49$ & 38 & 9 \\
\hline 7 & M & 41 & 42 & $84 / 68 / 58$ & 42 & 18 \\
\hline
\end{tabular}

$\mathrm{BMI}$ - body mass index; \%EWL - percentage of excess weight loss; F-female, $\mathrm{M}$ - male. 
observation lasted 3 days and each of the 4 patients underwent control abdominal contrast X-ray in order to check stomach tightness.

Two patients, in whom 28 and 32 months after LAGB body mass gain was observed along with lack of restriction after band regulation, heartburn, hyperacidity, and emesis, were referred for abdominal X-ray and CT.

Diagnostics were performed by means of an endoscopy of the upper gastrointestinal tract repeated several times. It revealed a partial migration of the gastric band (1/4-1/3) and its migration outside the stomach lumen was the cause of the aforementioned symptoms.

The patients were qualified for laparoscopic surgery, which was performed using 2 trocars $(10 \mathrm{~mm}$ and $15 \mathrm{~mm}$ ) along with a harmonic knife or LigaSure ${ }^{\mathrm{TM}}$. In both cases, the band was removed. In 1 case, stomach wall perforation was stitched and in another case, due to its location (the posterior stomach wall), it was impossible.

In both cases, a tube was placed into the stomach in order to drain the area of band migration. In the case where the perforation of the posterior wall of the stomach was impossible to stitch, lack of tightness lasted for 15 days.

\section{Discussion and conclusions}

The most effective treatment of obesity is surgery. ${ }^{10}$ It leads to permanent body mass loss, improves the quality of life and, in the majority of cases, eliminates co-morbidities such as diabetes, hypertension or hyperlipidemia. ${ }^{11}$ Due to the increase of demand, new bariatric centers are launched both worldwide and in Poland, and, along with that fact, the number of reports about the efficiency of obesity treatment and specialization is constantly growing.

The first LAGB was performed by Hallberg and Forsell in 1993. ${ }^{12}$ Between 2003 and 2008, this was the most frequently applied method worldwide. ${ }^{13}$ In 2011, Roux-en-Y gastric bypass (RYGB) was a leading procedure $-46.6 \%$ of surgeries, followed by sleeve gastrectomy (SG) - 27.8\%. The number of performed LAGB procedures has decreased within the last 4 years to $17.8 \% .^{14}$

Complications after LAGB include:

- those connected with port - disconnection from the drain, purulence in the place of port implantation;

- those connected with band - band slippage, pouch dilatation, migration to the stomach lumen, and band erosion;

- other - heartburn and hyperacidity, emesis.

Cobourn et al. from Surgical Weight Loss Clinic in Mississauga, Canada, conducted an analysis of the results based on an observation of 2815 obese patients after LAGB between May 2005 and January 2011. It was stated that complications occurred in 238 (8.5\%) patients, including 118 (4.2\%) patients experiencing band slippage, 14 (0.5\%) with band migration and erosion, and $35(1.2 \%)$ with symptoms of port and drain disconnection. ${ }^{15}$ Other complications included wound infection near the port ( $0.4 \%$ of cases), and intraperitoneal bleeding (0.1\%).

In comparison, Mittermair et al. from Medical University of Innsbruck, Austria, published in 2008 their own results - the percentage of 107 patients under 25 years of age who underwent LAGB and suffered from band migration was $2.78 \%{ }^{16}$

A significantly higher number of patients after LAGB who suffered from band migration to the stomach lumen was noticed by Lanthaler et al. in another center in Innsbruck. According to their data from 2010, the aforementioned complication occurred in $20.5 \%$ of cases. The examined group consisted of 276 patients after LAGB between 1996 and $2000 .^{17}$

The causes of band migration formulated on the basis of own experience include:

- band migration to the gastrointestinal tract is connected with the fact that the band is produced from plastics and tissues in different patients react differently to such a product; it is manifested in, perioperatively noted, numerous peritoneal adhesions, fibrosis or scarring in the area of the implemented band;

- complications caused by the operating team - frequency of complications is strictly connected with the "learning curve" and the number of procedures performed by the operator;

- causes connected with the producer - a manufacturing defect;

- causes connected with the patient - lack of proper cooperation with the physician and neglecting postoperative recommendations.

The aforementioned complications indicate that the removal of a migrated band requires a multispecialistic operating team in case of surgical method alteration.

Therapeutical proceedings - surgical or endoscopic treatment in patients with a migrated band - is an individual matter depending on the type and the size of band dislocation. Treatment also depends on clinical symptoms and the general state of the patient. The experience of the operating team and the quality of the equipment also are important factors.

\section{References}

1. Bužga M, Holéczy $P$, Švagera Z, Švorc P Jr, Zavadilová V. Effects of sleeve gastrectomy on parameters of lipid and glucose metabolism in obese women -6 months after operation. Wideochir Inne Tech Maloinwazyjne. 2013;8(1):22-28.

2. James WP. The epidemiology of obesity: The size of the problem. J Intern Med. 2008;263(4):336-352.

3. Szydłowski K, Frask A, Michalik M, Ciesielski M, Budziński R, Orłowski M. Complications after surgical treatment of obesity based on own material. Wideochir Inne Tech Maloinwazyjne. 2008;3(2):45-52.

4. Fernandez AZ Jr, Demaria EJ, Tichansky DS, et al. Multivariate analysis of risk factors for death following gastric bypass for treatment of morbid obesity. Ann Surg. 2004;239(5):698-702.

5. Chakravarty PD, McLaughlin E, Whittaker D, et al. Comparison of laparoscopic adjustable gastric banding (LAGB) with other bariatric procedures: A systematic review of the randomized controlled trials. Surgeon. 2012;10(3):172-182. 
6. Póvoa AA, Soares C, Esteves J, et al. Simultaneous gastric and colic laparoscopic adjustable gastric band migration: Complication of bariatric surgery. Obes Surg. 2010;20(6):796-800.

7. Hady RH, Dadan J, Sołdatow M, et al. Complications after laparoscopic gastric banding in own material. Wideochir Inne Tech Maloinwazyjne. 2012;7(3):166-174.

8. Wierzbicki Z, Lisik W. Przygotowanie chorego do operacji bariatryCznej. Medycyna Praktyczna Chirurgia. 2011;5:19-21.

9. Frieda M, Hainerb V, Basdevantc A, et al. Interdisciplinary European guidelines on surgery of severe obesity. Obes Facts. 2008;1(1):52-59.

10. Maggard MA, Shugarman LR, Suttorp M, et al. Meta-analysis: Surgical treatment of obesity. Ann Intern Med. 2005;142(7):547-559.

11. Hady RH, Dadan J, Gołaszewski P, Safiejko K. Impact of laparoscopic sleeve gastrectomy on body mass index, ghrelin, insulin and lipid levels in 100 obese patient. Wideochir Inne Tech Maloinwazyjne. 2012;7(4):251-259.
12. Abalikšta T, Brimas G, Strupas K. Laparoscopic adjustable gastric banding. A prospective randomized study comparing the Swedish adjustable gastric band and the MiniMizer Extra: One-year results. Wideochir Inne Tech Maloinwazyjne. 2011;6(4):207-216.

13. Buchwald H, Oien DM. Metabolic/bariatric surgery worldwide 2008. Obes Surg. 2008;19(12):1605-1611.

14. Buchwald H, Oien DM. Metabolic/bariatric surgery worldwide 2011. Obes Surg. 2013;23(4):427-436.

15. Cobourn C, Chapman MA, Ali A, Amrhein J. Five-year weight loss experience of outpatients receiving laparoscopic adjustable gastric band surgery. Obes Surg. 2013;23(7):903-910.

16. Mittermair R, Aigner F, Obermüller S. High complication rate after Swedish adjustable gastric banding in younger patients $\leq 25$ years. Obes Surg. 2009;19(4):446-450.

17. Lanthaler M, Aigner F, Kinzl J, Sieb M, Cakar-Beck F, Nehoda H. Longterm results and complications following adjustable gastric banding. Obes Surg. 2010;20(8):1078-1085. 